\title{
MODELOS DE MEDIDAS DE ACCIÓN POSITIVA EN LOS PAÍSES MIEMBROS DE LA UNIÓN EUROPEA
}

\author{
DRA. MARÍA ÁNGELES MARTÍN VTDA \\ Universidad de Granada \\ Universidad de Regensburg (Alemania) ${ }^{1}$
}

SUMARIO

1. Introducción

2. Previsión constitucional de medidas de acción positiva

3. Medidas incisivas de ácción positiva en favor de colectivos distintos de las mujeres

4. Medidas de acción positiva en favor de las mujeres

\section{INTRODUCCIÓN}

Cada cierto tiempo emerge con gran intensidad en el seno de la opinión pública española un debate que sólo muy recientemente ha empezado a traducirse en dos Comunidades Autónomas (Castilla-La Mancha y Baleares) en realidades legislativas concretas, siguiendo la estela de lo ocurrido en otros países de nuestro entorno: el debate sobre las medidas de acción positiva en favor de las mujeres. Es éste un tema respecto al que, en el nivel teórico, existen discrepancias muy notables entre unas opciones políticas y otras, sobre todo cuando el debate versa acerca de las modalidades más incisivas que estas medidas pueden revestir.

1. La doctora María Ángeles Martín Vida ha sido hasta agosto de 2003 Becaria Postdoctoral de Investigación en la Cátedra de Derecho Público (Prof. Arnold) de la Universidad de Regensburg (Alemania). Esta publicación es en parte posible gracias a la Beca Postdoctoral del Ministerio Español de Educación, Cultura y Deporte de la que disfrutó. Actualmente trabaja como colaboradora científica en el Instituto de Derecho Comparado de la Universidad de Osnabrück (Alemania). 
En el marco de los Estados miembros de la Unión Europea el fenómeno de las acciones positivas parece imparable, más aún tras el decisivo impulso que ha supuesto el Tratado de Amsterdam. Sin embargo, no en todos los países se ha puesto en práctica el mismo tipo de medidas, ni en los mismos ámbitos, ni, por supuesto, los límites constitucionales a los que las mismas están sujetas son en todo caso los mismos. La referencia a estos sistemas nos puede servir para conocer modelos en los que pudieran quizá llegar a inspirarse nuestros legisladores en el futuro para dotar de una base legal específica a una materia que en España (salvo las dos excepciones citadas de Castilla-La Mancha y Baleares en el campo de las cuotas electorales) carece de ella. Es interesante conocer las técnicas adoptadas en este ámbito en otros países comunitarios (también en Noruega), aunque sin caer en la tentación de llegar a considerar ninguna de ellas como la panacea, y sin olvidar la necesidad de adaptar dichas técnicas a las circunstancias concretas de nuestro país, que no necesariamente van a coincidir con las de los países de nuestro entorno. Esta aproximación comparada puede permitirnos, y eso es lo positivo, aprender de otras experiencias, analizando las ventajas que se han derivado de su implantación en otros Estados y los problemas que han llevado consigo o que no se han logrado solucionar ${ }^{2}$.

\section{PREVISIÓN CONSTITUCIONAL DE MEDIDAS DE ACCIÓN POSITIVA}

Son varios los países en los que se hace una referencia expresa a las medidas de acción positiva en el texto de las respectivas Normas Fundamentales. Algunas Constituciones han sido incluso recientemente modificadas para incorporar tal referencia, una vez que se ha tomado conciencia de que una percepción tradicional, de carácter simétrico, de lo que significa la prohibición de discriminación por razón de sexo no basta para garantizar una auténtica igualdad real de oportunidades para las mujeres en los distintos ámbitos.

En Alemania, país del que proceden tres de los cinco casos resueltos hasta ahora sobre acciones positivas por el Tribunal de Justicia de las Comunidades Europeas (en adelante, TJCE), y uno de los países más avanzados en esta materia $^{3}$, la jurisprudencia del Tribunal Constitucional Federal venía tradicionalmen-

2. No nos ocupamos en este trabajo de la problemática específica de las cuotas electorales. Las líneas generales de ese estudio, con referencias concretas al Derecho comparado, están apuntadas en mi trabajo Fundamento y límites constitucionales de las medidas de acción positiva. Madrid: Civitas, 2003, al cual me remito.

3. Las cifras de infrarrepresentación femenina en los niveles de mayor responsabilidad tanto en la Administración como en la empresa privada alemanas son, sin embargo, similares a las de otros países europeos. Me remito a los datos que aporta el folleto descriptivo del Programm *Frau und Berufw: Aufbruch in der Gleichstellungspolitik. Berlín: Bundesministerium für Familie, Senioren, Frauen und Jugend, 1999, en especial pp. 6-7, un programa que está desarrollando el Ministerio Federal de Familia, Ancianos, Mujeres y Juventud de cara a elevar los niveles de igualdad de oportunidades de las mujeres en todos los ámbitos y a facilitarles que puedan compatibilizar responsabilidades familiares y profesionales. 
te admitiendo no sólo que la Ley Fundamental de Bonn (en adelante, GG) permitía sino que obligaba a adoptar medidas orientadas a poner fin a las discriminaciones por razón de sexo existentes, aceptando incluso la posibilidad de prever diferencias de trato jurídico en favor del colectivo tradicionalmente marginado que permitiesen a las mujeres superar la situación de desigualdad de hecho en que se hallaban ${ }^{4}$ y corregir los casos de infrarrepresentación femenina en ciertos niveles. El conflicto constitucional se centraba (y se sigue centrando) en la compatibilidad entre las medidas de tratamiento preferente en favor de las mujeres y la protección de los trabajadores y estudiantes varones, de acuerdo con los apartados 2 y 3 del artículo 3 GG. La constitucionalidad de las medidas de acción positiva, sin embargo, recibió un impulso decisivo con la reforma del apartado 2 del artículo $3 \mathrm{GG}$ en octubre de 1994. Al apartado 2 se le añadió un inciso final que contiene un mandato expreso a los poderes públicos de cara a la promoción de la igualdad real entre hombres y mujeres y a la remoción de los obstáculos que la dificultan, redactado del siguiente modo: “hombres y mujeres gozan de los mismos derechos. El Estado favorecerá la realización efectiva de la igualdad entre bombres y mujeres y actuará con el fin de eliminar las desigualdades existentes, ${ }^{5}$.

La Ley Fundamental decía simplemente antes de la reforma de 1994 que «bombres y mujeres gozan de los mismos derechos" (art. 3.2 GG) y que "nadie puede ser discriminado o privilegiado por razón de su sexo. (art. $3.3 \mathrm{GG}$ ), lo que llevó a algunos autores a apreciar la existencia de una prohibición absoluta para el legislador de establecer tratamientos jurídicos diferenciados en función del rasgo "sexo", prohibición que englobaba naturalmente a las medidas de acción positiva ${ }^{6}:$ si las

4. "Respecto a la cuestión de si una medida discrimina injustamente a las mujeres por razón de su sexo, el artículo 3.2 GG no contiene [respecto al artículo $3.3 \mathrm{GG}$ ] ninguna exigencia especial o más amplia. El contenido normativo del artículo $3.2 \mathrm{GG}$ que va más allá de la prohibición de discriminación del artículo 3.3 GG consiste en que establece un mandato de paridad de tratamiento y que éste se extiende también a la realidad social. La frase "bombres y mujeres gozan de los mismos derechos" pretende no sólo eliminar las normas jurídicas que vinculan ventajas y desventajas a rasgos relacionados con el sexo, sino también establecer de cara al futuro la igualdad de derechos entre los sexos (...) Las desventajas fácticas que afectan típicamente a las mujeres ban de ser, por exigencia del articulo $3.2 \mathrm{GG}$, compensadas mediante medidas de favorecimientow (sentencia del Tribunal Constitucional Federal Alemán sobre la prohibición del trabajo nocturno de las mujeres, BVerfGE 85, 191 (206f) - la traducción del alemán es mía-). No se pronuncia el Tribunal Constitucional Federal Alemán acerca de si tales medidas de favorecimiento serían legítimas incluso si comportasen desventajas concretas para varones concretos.

5. "Der Staat fördert die tatsächliche Durchsetzung der Gleichberechtigung von Frauen und Männern und wirkt auf die Beseitigung bestebender Nachteile bin. Esta reforma, aprobada por el Bundestag el 27 de octubre de 1994, entró en vigor el 15 de noviembre de ese mismo año.

6. Sobre esta discusión doctrinal, puede verse DöRING, Matthias: Frauenquoten und Verfassungsrecbt (die Rechtmäßigkeit "umgekebrter Diskriminierung" nach US-amerikanischen Verfassungsrecht und ibre Bedeutung für die Verfassungsmäßigkeit gesetzlicher Frauenquoten auf dem Arbeitsmarkt der deutschen Privatwirschaft). Berlin: Duncker \& Humblot, 1996 (Schriften zum öffentlichen Recht, Band 694), pp. 184 y ss, a quien sigo en este punto. También FISAHN, Andreas: "Rechtmäßigkeit von "Quotenregelungen" nach Änderung des Art. 3.II GG". Neue Justiz, núm. 7, 1995, pp. 352 y ss. Las únicas diferencias de tratamiento jurídico justificadas serían, en la jurisprudencia del Tribunal de Karlsruhe, aquéllas vinculadas con diferencias “biológicas o funciona- 
mujeres han padecido en el pasado en Alemania ciertas desventajas derivadas de la vulneración del principio de igualdad y de la prohibición de discriminación, era deber del legislador ahora asegurar el respeto a las normas contenidas en los apartados 2 y 3 del artículo 3 GG, pero lo que no podía hacer era invertir la norma y elevar su contrario a principio jurídico. Se infería así del art. 3 GG el principio sex-blindness (neutralidad ante el sexo), que se correspondería con una sociedad meritocrática en la cual cada uno es tratado según sus méritos, y no según se pertenencia a uno u otro sexo. Los apartados 2 y 3 del artículo 3 GG reconocían, pues, ante todo, un derecho individual que permitía reaccionar frente a tratamientos estatales desiguales, discriminaciones y preferencias por razón de sexo, sin que en ningún caso el Tribunal Constitucional Federal hubiese deducido de ellos una obligación estatal positiva de acción?: los poderes públicos sólo estaban obligados a cumplir y garantizar la dimensión jurídica del principio de igualdad y el derecho fundamental del artículo $3.2 \mathrm{GG}$, en parte porque se les consideraba incapaces de garantizar la igualdad en su dimensión fáctica o real.

Otros autores, sin embargo, tomando también como referencia la antigua redacción del artículo 3 GG dedujeron de él una norma unilateral que autorizaba los tratamientos diferenciados en favor de las mujeres de cara a lograr su parificación con los varones. La unilateralidad de la norma se asociaba por un lado con la existencia en el apartado 2 de un componente grupal que no aparecía en el apartado 3 , según estos autores ${ }^{8}$. Ese elemento grupal identificaba a las mujeres como colectivo tradicionalmente discriminado que aspiraba a la equiparación real de sus oportunidades con los varones, incluso mediante tratamientos diferenciados temporales. Una medida de tratamiento preferente en favor de las mujeres se inscribiría en el ámbito de ese apartado 2, norma especial, y no en la prohibición genérica de discriminación individual dél apartado 3 , norma general'.

les" existentes entre hombres y mujeres, y que marcan de forma decisiva los comportamientos vitales que el Derecho tiene que regular (ibidem, p. 353). La referencia a las "diferencias funcionales" parece peligrosamente amplia, pues por esa vía se puede llegar a justificar y a mantener el reparto tradicional de roles entre hombres y mujeres.

7. Era la opinión también de SuERBAUM, Joachim: "Affirmative action. Positive Diskriminierung im amerikanischen und im deutschen Recht. Der Staat, núm. 3, 1989, pp. 438-439: el artículo 3.3 GG cierra expresamente la puerta a la posibilidad de establecer preferencias de trato en favor de las mujeres para lograr la consecución de una igualdad real entre ellas y los varones. Este autor no detectaba en el artículo 3.2 GG (en su redacción antigua, sin el último inciso) la existencia de ningún mandato constitucional dirigido a los poderes públicos para que estableciesen una igualdad real entre hombres y mujeres.

8. Vid. DörING, M., op. cit., pp. 198 y ss.

9. Slupik es de esta opinión. Aprecia en el artículo 3.2 GG (incluso antes de la reforma) un especial mandato de promoción colectiva exclusivamente a favor de las mujeres, mientras que el apartado 3, por el contrario, consagra una prohibición de discriminación individual referida a ambos sexos; una colisión entre la prohibición individual de discriminación y la exigencia colectiva de promoción debe ser solucionada en favor de la última (SLuPIK, Vera: Die Entscheidung des Grundgesetzes für Parität im Geschlechterverbältnis. Berlín: 1988, pp. 79 y ss, citada por DöRiNG, M., op. cit., p. 208, nota 181). 
Para otros autores, sin embargo, no era que la medida de acción positiva no cayese en el ámbito del artículo 3.3 GG por serle de aplicación una norma especial, la del $3.2 \mathrm{GG}$, sino que en tales casos no habría propiamente una discriminación en el sentido del artículo 3.3 GG. Por otro lado, la unilateralidad de la norma se derivaba también de la cláusula del Estado social (art. 20.1 GG), que reforzaba la dimensión jurídica objetiva del artículo 3.2 GG, y que obligaría al legislador a hacer realidad también en la vida social la igualdad de los sexos, sin que para el cumplimiento de este mandato se le diese al órgano normador ninguna directiva vinculante sobre la clase de medidas que podía utilizar. Era la opinión, por ejemplo, sostenid $₫$ por Benda, incluso antes de la reforma constitucional: el artículo 3.2 GG reconocía un derecho subjetivo individual, del que también eran titulares los varones, pero contenía igualmente una opción axiológica en favor de la realización práctica de la igualdad entre los sexos en la realidad social, opción axiológica que se vinculaba con el principio del Estado social (y que habría quedado desde 1994 confirmada con la adición del segundo párrafo). Según este autor no había (al menos antes de la reforma, entendemos) una obligación para los poderes públicos de actuar en ese sentido, pero sí que estaban facultados para ello, pudiendo incluso sacrificar en casos concretos el derecho subjetivo individual de los varones cuando la necesidad de hacer realidad la opción axiológica objetiva y reforzar con ello el Estado social constituyese un interés preeminente ${ }^{10}$.

La unilateralidad del artículo 3.2 GG parece haber quedado definitivamente confirmada con la reforma de 1994: del artículo 3.2 GG se extrae ahora no solamente una obligación de eliminar las normas jurídicas que asocian ventajas o desventajas con el rasgo "sexo" (o género), sino también una imposición para lograr en el futuro la igualdad de tratamiento de los sexos y la armonización de las relaciones sociales. Es eso lo que el artículo $3.2 \mathrm{GG}$ ha aportado siempre al artículo $3.3 \mathrm{GG}$, la evidencia de que la prohibición de discriminación (y más la prohibición de discriminación por razón de sexo) no aparece en la Constitución como un mandato simétrico, sino que persigue favorecer la posición de aquéllos que tradicionalmente se han visto marginados, en aras de lograr mayores cotas de igualdad real. El apartado 3 recoge claramente en su tenor literal una prohibición de discriminación por razón de sexo, mientras que el apartado 2 ha tenido siempre un sentido gramatical más amplio, más allá de dicha prohibición de discriminación, pues de lo contrario sería superfluo ${ }^{11}$. Tiene una orientación finalista, vinculante para los poderes

10. DöRING, M., op. cit., p. 439, que envía a BENDA, Ernst: Notwendigkeit und Möglichkeit positiver Aktionen zugunsten von Frauen im öffentlichen Dienst. Gutacbten im Auftrag der Senatskanzlei - Leitstelle Gleichstellung der Frau - der Freien und Hansestadt Hamburg, 1986, pp. 118 y ss.

11. El Tribunal Constitucional Federal Alemán ha sustentado en todo caso su jurisprudencia en materia de igualdad entre sexos casi exclusivamente sobre el artículo 3.2 , sin resolver la duda acerca de la relación que vincula a dicho apartado con el apartado 3 , lo cual ha dejado tradicionalmente abierta la puerta a quienes afirmaban que el contenido de ambos preceptos (al 
públicos, una vez que se constata que la afirmación "los hombres y las mujeres gozan de los mismos derechos, no se corresponde con la realidad existente, orientación finalista que queda sin lugar a dudas confirmada tras la reforma de 1994 y la introducción del inciso final en el apartado 2 . Se encomienda al Estado el fomento de la rrealización fáctica de la igualdad de trato entre hombres y mujeres, aunque es cierto que dicho mandato no hace surgir paralelamente un derecho jurisdiccionalmente accionable a reclamar la puesta en marcha de determinadas medidas: la elección de los medios para la satisfacción de aquel fin queda en manos de una decisión discrecional de los poderes públicos ${ }^{12}$, si bien parece ser que hubo consenso en el seno de la Comisión Mixta Constitucional que trabajó en la reforma del artículo 3.2 en el sentido de considerar incompatibles con él en todo caso las medidas de tratamiento preferente que no exigen una determinada cualificación a los beneficiarios de las mismas ${ }^{13}$ (opinión que, obviamente, no vincula al Tribunal Constitucional, pero que puede ser un elemento valioso de interpretación auténtica cuando haya de enfrentarse en un caso concreto a la misión de desentrañar el sentido y el contenido de este precepto) ${ }^{14}$.

También en Austria ${ }^{15}$ ha sido la Ley Constitucional Federal objeto de reforma, en 1998, de tal modo que el Gobierno Federal, las Provincias y las autoridades locales han asumido el compromiso expreso de garantizar la igualdad real entre hombres y mujeres, admitiéndose específicamente en la Norma fundamental austríaca la constitucionalidad de las medidas de acción positiva orientadas a eliminar las desigualdades existentes entre $\operatorname{sexos}^{16}$. La Constitu-

menos antes de la reforma) era, en efecto, idéntico, y que nada cambiaría si el apartado 2 fuese eliminado.

12. La admisibilidad de las medidas de acción positiva en el marco del artículo 3 GG no supone automáticamente la constitucionalidad de todas ellas, en particular de aquéllas más incisivas que adopten la forma de reservas de plazas en favor de los miembros de los colectivos tradicionalmente marginados. El artículo 33.2 GG se erige también como límite a las medidas de tratamiento preferente en favor de tales sujetos en el ámbito de la Administración, pues exige que se respeten las exigencias del principio del mérito en el caso concreto del acceso a la función pública. El Tribunal Constitucional Federal Alemán no se ha pronunciado todavía sobre la admisibilidad de los sistemas de reserva de plazas y sobre sus límites.

13. Döring, M., op. cit., p. 211.

14. Sobre la interpretación del nuevo inciso añadido al artículo $3.2 \mathrm{GG}$ recomiendo la lectura de FISAHN, A., op. cit., pp. 352 y ss.

15. Pueden verse más ampliamente al respecto sendas ponencias, publicadas con el mismo título, de Lilian HOFMEISTER y Alfred MAYER: «Positive Aktionen für Frauen im öffentlichen Dienst Österreichs/Positive action for women in the Public Service in Austriaw. En KNIPP, Margit y SPORRER, Anna (eds.): Frauenförderung im öffentlichen Dienst der Mitgliedstaaten und Institutionen der Europäischen Union / The promotion of women in the Public Service of the Member States and Institutions of the European Union. Viena: European Commission, DG V - Austrian Federal Academy of Public Administration, 1998, pp. 115 y ss., y 144 y ss., respectivamente.

16. Dice textualmente el nuevo apartado 2 del artículo 7 de la Constitución austríaca: " $L a$ Federación, las provincias y las comunidades locales asumen un compromiso en favor de la igualdad real entre hombres y mujeres. Se admiten las medidas orientadas a promover la igualdad de hecho de bombres y mujeres, en especial mediante la eliminación de las desigualdades fácticas existentes. 
ción finlandesa de 1995 ha incorporado asimismo una referencia expresa al objetivo genérico de consecución de la igualdad real. La Ley constitucional sueca de 1975, después de prohibir la discriminación por razón de sexo, autoriza la adopción de medidas orientadas a lograr la igualdad real de las mujeres ${ }^{17}$.

En Luxemburgo esa reforma constitucional aún no se ha producido. El artículo 11.2 de la Constitución de este país dice actualmente que "los luxemburgueses son iguales ante la lejs, habiéndose interpretado siempre que el término "luxemburgués" incluye también a las mujeres. Ahora bien, hay en marcha un proyecto (siguiendo los dictados del Convenio para la Eliminación de Todas las Formas de Discriminación contra las Mujeres, que entró en vigor en Luxemburgo en marzo de 1989) para reformar este precepto constitucional con un doble propósito: primero, que se haga una referencia expresa a la igualdad ante la ley (igualdad jurídica) de hombres y mujeres, y segundo, para dotar de apoyo constitucional expreso a las medidas legales temporales orientadas a favorecer la igualdad de oportunidades entre hombres y mujeres ${ }^{18}$, medidas para cuya adopción la regulación actual del artículo 11.2 comporta bastantes problemas. La idea es dejarlo redactado como sigue: "las mujeres $y$ los hombres son iguales ante la ley. La ley podrá establecer medidas que favorezcan la igualdad de oportunidades en el ejercicio efectivo de los derechos. No parece previsible en ningún caso que las acciones positivas lleguen a imponerse constitucionalmente de forma obligatoria.

La más reciente reforma constitucional en este sentido se ha producido en Bélgica en febrero de 2002. Al artículo 10 de la Constitución belga ("no bay en el Estado distinción alguna de estamentos. Los belgas son iguales ante la ley; sólo ellos son admitidos a los empleos civiles y militares, salvo las excepciones que puedan ser establecidas por una ley para casos particulares), se ha añadido un párrafo que incorpora una referencia expresa a la igualdad entre hombres y mujeres. Asimismo se ha dado entrada en la Constitución a través del nuevo artículo 10bis a un mandato a los legisladores para que garanticen el igual ejercicio de sus derechos a hombres y mujeres, en especial en lo que se refiere al acceso a los cargos públicos electivos. Se indica igualmente que ambos sexos habrán de estar representados en los gobiernos federal y regionales, y que legalmente se garantizará en el futuro también esa presencia de ambos sexos en los gobiernos locales.

La nueva Constitución griega, por su parte, que entró en vigor en abril de 2001, no permite ninguna excepción al principio de igualdad de género, en

17. Art. 16: "Ninguna ley ni ninguna otra norma podrá suponer la discriminación de ningún ciudadano por razón de sexo, a menos que la disposición relevante forme parte de esfuerzos para obtener la igualdad entre bombres y mujeres o baga referencia al servicio militar obligatorio o a cualquier otro servicio nacional obligatorio.

18. Avis de la Commission de l'Égalité des chances entre femmes et bommes et de la promotion féminine, de 18 de noviembre de 1998, relativo al proyecto de reforma del artículo 11 de la Constitución (documento parlamentario núm. 3923). 
su comprensión tradicional. La antigua Constitución sustituyó la antigua autorización de derogaciones puntuales de la prohibición de no discriminación por razón de sexo por una cláusula que expresamente permitía las medidas de acción positiva, en particular en favor de las mujeres. Ambas referencias han quedado suprimidas con la nueva Constitución ${ }^{19}$.

En algunos de los países donde la Constitución no hace una referencia expresa a la admisibilidad de las medidas diferenciadas de tratamiento jurídico en favor de los miembros de colectivos tradicionalmente marginados, han sido los máximos órganos que asumen la labor de control de constitucionalidad de las normas y de protección de derechos fundamentales los que han ido construyendo paulatinamente una doctrina que en general confirma, con más o menos matices, la constitucionalidad de este tipo de medidas.

En el Reino Unido ${ }^{20}$ la concepción dominante es la que considera la no discriminación como un derecho individual, y no como una herramienta para corregir desventajas sociales y económicas sufridas por los miembros de grupos que han padecido tradicionalmente fenómenos de marginación y exclusión. No hay un componente de asimetría en la percepción británica de los fenómenos de discriminación, salvo quizá en el caso de los discapacitados. Es por eso que, en general, las medidas de acción positiva no son empleadas en Gran Bretaña salvo en situaciones muy excepcionales y siempre objeto de interpretación restrictiva, dado su carácter de auténtica excepción a la regla general que es el principio de igualdad y la prohibición de discriminación, y en todo caso suelen adoptar las formas menos incisivas.

El Consejo Constitucional francés, por su parte, entiende tradicionalmente que el principio de igualdad (consagrado al máximo nivel normativo tanto en el texto de la propia Constitución de 1958 como en la Declaración de Derechos de 1789 y en el Preámbulo de la Constitución de 194621) no se opone ni

19. Mientras, sin embargo, se mantienen en Grecia las cuotas que limitan al 15\% el número de mujeres que pueden acceder a las Academias de Policía, una limitación claramente contraria al Derecho comunitario, que se intenta justificar alegando que para el ejercicio de las funciones propias de la labor policial se requieren unas características físicas que los hombres poseen en mucha mayor medida que las mujeres, y que el Consejo de Estado griego ha considerado acorde con la Constitución y no incompatible con el Derecho comunitario. La cuota que limitaba su acceso a las Academias Militares ha sido eliminada recientemente.

20. Sobre la concepción británica del principio de igualdad y de la prohibición de discriminación, puede verse más ampliamente BOURN, Colin y WHITMORE, John: Anti-discrimination Law in Britain. Londres: Sweet \& Maxwell, 1996.

21. Sobre la atribución de pleno valor constitucional al Preámbulo de la Constitución francesa de 1958 y, con ello, a la Declaración de Derechos de 1789 y al Preámbulo de la Constitución de 1946, lo que supone poner en manos del Consejo Constitucional el control de la actividad del legislador en materia de derechos y libertades, me remito a TAJAura TEJADA, Javier: "Los derechos fundamentales en la Constitución francesa de 1958: vigencia actual de la Declaración de Derechos del Hombre y del Ciudadano de 1789". En VVAA: Estudios de Derecho Público (Homenaje a Juan José Ruiz-Rico). Madrid: Tecnos, 1997, pp. 413 y ss. Sobre la reforma de la Constitución Francesa en 1999 para permitir la introducción en este país de las candidaturas electorales paritarias, me remito a mi trabajo Fundamento y limites. 
a que el legislador regule de modo diferente situaciones diferentes ni a que derogue la igualdad por razones de interés general siempre que, en uno y otro caso, la diferencia de trato resultante esté en relación directa con el fin de la ley que la ha establecido.

\section{MEDIDAS INCISIVAS DE ACCIÓN POSITIVA EN FAVOR DE COLECTIVOS DISTINTOS DE LAS MUJERES}

Son varios los países que prevén medidas incisivas de acción positiva (incluso en forma de reservas de plazas) en favor de colectivos distintos de las mujeres cuya constitucionalidad no plantea mayores problemas. Es lo que ocurre, por ejemplo, en Bélgica al máximo nivel. Derivado de la configuración del Estado belga como Estado federal pluricomunitario, la Constitución de Bélgica establece en su artículo 67.2 que ha de asegurarse una representación mínima de electos bruselenses en el Senado; en el artículo 99.2, que ha de garantizarse que en el Consejo de Ministros haya un número igual de ministros de lengua francesa y de lengua neerlandesa; y lo mismo ocurre en la composición del Gobierno de la región de Bruselas capital ${ }^{22}$.

Algo parecido ocurre en Italia: los artículos 61 y 62 del Estatuto del Trentino-Alto Adige ${ }^{23}$, con fundamento en el artículo 6 de la Constitución Italiana, reclaman la aplicación del principio de "proporcionalidad étnica" en la composición de los órganos colegiados de los entes públicos locales y de las oficinas estatales de la provincia de Bolzano, previendo el reparto de los distintos puestos entre los diversos grupos lingüísticos en función de la importancia numérica de tales grupos según el censo de población. La Corte Costituzionale ha admitido en diversas sentencias ${ }^{24}$ la constitucionalidad de tales previsiones estatutarias, que se fundamentan en el principio de protección de las minorías lingüísticas, un principio que admite incluso la adopción de esta clase de medidas positivas orientadas a preservar las peculiares características culturales y étnicas de tales colectivos. La reforma del Estatuto en 1972 introdujo incluso el principio de la "representación garantizada" a favor del grupo lingüístico ladino tanto en los consejos regionales y provinciales de Bolzano

22. FAVOREU, Louis: "Principio de igualdad y representación política de las mujeres: cuotas, paridad y Constitución". Revista Española de Derecbo Constitucional, núm. 50, mayo-agosto 1997 , pp. $25-26$.

23. Vid. en relación a esto CINANNI, Giovanni: «Leggi elettorali e azioni positive in favore delle donne". Giurisprudenza Costituzionale, núm. 5, 1995, en especial pp. 3288 y ss. También PIERGIGLI, Valeria: Lingue minoritarie e identità culturali. Milán: Giuffrè Editore, 2001, en especial pp. 205 y ss., y 442 y ss. El Estatuto de la región Trentino-Alto Adige prevé en su artículo 62 que "las leyes sobre elecciones al Consejo regional y al Consejo provincial de Bolzano, asi como las normas sobre la composición de los órganos colegiados de los entes públicos locales de la provincia de Bolzano, garantizarán la representación del colectivo lingüístico ladino". 1987.

24. Entre otras, sentencias núm. 86 de 16 de abril de 1975, y núm. 289 de 28 de julio de 
como en la constitución de los órganos colegiados de los entes públicos locales en esta provincia. De este modo, se prevé que si ningún candidato ladino resulta elegido en el proceso electoral ordinario para la composición de estos órganos, se adjudica automáticamente un puesto en cualquier caso al candidato ladino que haya obtenido el mayor número de votos, para de este modo asegurar la representación del colectivo minoritario en el seno de tales órganos $^{25}$. La reforma del Estatuto del Trentino-Alto Adige llevada a cabo en 2001 ha confirmado la garantía de representación del grupo lingüístico ladino en el seno del consejo provincial de Bolzano y en los órganos colegiados de los entes locales de esa provincia, y asegura su presencia además en las juntas provinciales y regionales, nuevamente mediante un sistema de reserva de puestos.

En otros ámbitos, hay una decisión del Consejo Constitucional Francés, de 25 de enero de $1995^{26}$, en la que éste ha admitido expresamente que las medidas de acción positiva en favor de colectivos con especiales dificultades de inserción en el mundo laboral no vulneran el principio de igualdad, a la luz de las dificultades y obstáculos que afectan a la inserción profesional de tales sujetos, pero sin entrar a especificar si tal diferencia de trato jurídico se justifica por la existencia de una diferente situación de hecho o por la concurrencia de una razón de interés general. Lo que acepta expresamente en esta Decisión es esa concepción de la igualdad, como igualdad real y no sólo formal, que maneja el legislador y por ello justifica que éste emplee medidas de acción positiva para corregir las desigualdades fácticas que afectan a ciertos colectivos, pero siempre que éstos no se definan precisamente en función de uno de los criterios expresamente contenidos en la prohibición constitucional de discriminación. De hecho, en el ámbito de la función pública, el Consejo Constitucional ha admitido la constitucionalidad de las medidas legislativas que favorecen directamente el acceso de los habitantes nativos de Nueva Caledonia a la función pública de este territorio francés de ultramar para com-

25. En la sentencia núm. 233 de 10 de junio de 1994, la Corte Costituzionale se ocupó de una ley ordinaria de la región Trentino-Alto Adige que extendía la regulación de la reserva de puestos a favor de la minoría ladina también a la composición de los consejos municipales y de las juntas de la provincia de Bolzano. Fue declarada inconstitucional. La Corte admitió que el principio de protección de las minorías lingüísticas podía justificar tratamientos diferenciados en favor de tales grupos, en aras de la igualdad sustancial, y de hecho así se preveía en el Estatuto de la región, pero que tal protección no podía superar ciertos límites, a efectos de no vulnerar otros valores dignos de tutela (fundamentalmente, la igualdad del voto, artículos 3 y 48 de la Constitución Italiana - en adelante, $\mathrm{CI}-$ ); y, sobre todo (endureciendo con ello su postura respecto a la mantenida en la sentencia núm. 289 de 1987), que sólo una norma de rango constitucional (como el Estatuto), y no de rango legal, podría introducir en el ordenamiento medidas de esta naturaleza que afectan tan incisivamente a otros valores constitucionales. A ello añadió el razonamiento de que las garantías contenidas en el Estatuto en favor del grupo lingüístico ladino no son susceptibles de aplicación analógica a otros supuestos distintos de los previstos en el mismo, como la composición de los consejos municipales y de las juntas de la provincia de Bolzano, que era a los que se aplicaba la reserva de puestos contemplada en la ley regional objeto de controversia.

26. Decisión núm. 94-357 DC. 
pensar su más que notable infrarrepresentación en ese ámbito y conjurar también así los peligros de révueltas que pudiesen afectar a la estabilidad política de dicho territorio ${ }^{27}$. Una medida similar aplicable a un colectivo definido por su sexo o por su raza no habría sido aceptada por el Consejo Constitucional por considerarla abiertamente contraria a la prohibición constitucional de discriminación.

En Irlanda del Norte, donde se promulgó en 1989 la Fair Employment (Northern Ireland) Act, se prevé expresamente la posibilidad de emplear, respetando en todo caso el criterio del mérito, medidas de acción positiva, incluso en forma de objetivos numéricos, para garantizar el equilibrio de los miembros de las dos comunidades religiosas, católicos y protestantes. No hay previsiones normativas similares en todo el Reino Unido en favor de las mujeres, ni en favor de minorías raciales, pero sí las hay en favor de los discapacitados: la Disability Discrimination Act de 1995 permite todo tipo de tratamientos jurídicos más favorables para los discapacitados, tanto su contratación preferente como incluso la reserva de plazas, dado que el no discapacitado no puede en ningún caso recurrir la decisión del empleador desfavorable para él. Tales medidas no serían admitidas de ser aplicadas a otros colectivos. También en Francia hay previstos sistemas de reserva de plazas en favor de los discapacitados. En concreto, el artículo L. 323-1 del Code du Travail (ley francesa 87-517, de 10 de julio de 1987) obliga a los empleadores públicos y privados que tengan contratados a más de veinte trabajadores a que reserven un seis por ciento de los puestos de trabajo a discapacitados ${ }^{28}$, pero también a víctimas de accidentes de trabajo o de enfermedades profesionales que les hayan supuesto una incapacidad permanente, a los titulares de pensiones de invalidez, a veteranos de guerra, a viudas de guerra, a huérfanos de guerra menores de veintiún años, y a las mujeres de inválidos que padezcan problemas mentales por haber servido en el frente ${ }^{29}$.

27. Decisión núm. 84-178 DC, de 30 de agosto de 1984 . Vid. al respecto MÉLin-SoucramaNIEN, Ferdinand: Le principe d'égalité dans la jurisprudence du Conseil Constitutionnel. París: Economica-Presses Universitaires d'Aix-Marseille, 1997 (Collection Droit Public Positif), pp. 235-236.

28. Una reserva de plazas del cinco por ciento se aplica también en Alemania en empresas públicas y privadas que empleen a más de veinte trabajadores $(\$ 5.1$ de la Ley Federal para asegurar la Integración de los Discapacitados en el Trabajo, el Empleo y la Sociedad, de 1986 (Schwerbehindertengesetz), tras la reforma de 29 de septiembre de 2000). En esa misma Ley se indica $(\$ 5.1 a)$ que ese porcentaje se elevará al seis por ciento desde el 1 de enero de 2003 si la cifra de discapacitados desempleados en octubre de 2002 no es al menos un veinticinco por ciento inferior a la cifra de discapacitados desempleados en octubre de 1999. En cualquier caso se autoriza al Gobierno federal a, con el acuerdo del Bundesrat, elevar o disminuir ese porcentaje hasta el diez o el cuatro por ciento, respectivamente, en función de las necesidades concretas de puestos de trabajo para discapacitados ( $\$ 5.2)$.

29. También hay previstas reservas de plazas en favor de diversos colectivos en el $₫ 10$, apartado 1, de la Ley Federal sobre Pensiones de antiguos Soldados del Ejército Alemán y sus Familiares Supérstites de 1987 (Soldatenversorgungsgesetz), así como en los $\$ \$ 3$ y ss de la Ley del Land Renania del Norte-Westfalia sobre un Bono de Aprovisionamiento para Mineros, de 1948 (Bergmannsversorgungsscheingesetz). 


\section{MEDIDAS DE ACCIÓN POSITIVA EN FAVOR DE LAS MUJERES}

Quizá el ejemplo italiano pueda servir para ilustrar cómo el cambio de percepción de lo que significa la prohibición de discriminación por razón de sexo, esto es, el carácter unilateral y no simétrico de la misma, ha tenido su reflejo en el plano legal (igual que, como pudimos comprobar anteriormente, lo va teniendo poco a poco en el plano constitucional en países donde la proclamación del principio de igualdad se había llevado a cabo bajo la inspiración de los cánones liberales y sin referencias expresas a la igualdad real como objetivo orientador de la actuación de los poderes públicos). En 1977 se elaboró en Italia, en aplicación de las Directivas comunitarias 75/117 y 76/207, una ley, la núm. 903 de ese año (Ley sobre la paridad de tratamiento entre hombres y mujeres en materia de trabajo), cuyo objetivo era garantizar a las trabajadoras la igualdad en las condiciones de trabajo. La igualdad garantizada por esta ley era una igualdad de carácter eminentemente formal, y ello, junto a la falta de un soporte institucional adecuado, y a ciertos factores estructurales, incidió en su escasa eficacia a la hora de garantizar la igualdad de oportunidades de trabajadores y trabajadoras ${ }^{30}$, aunque sirvió para dotar al trabajo femenino de una dignidad que hasta entonces no se le había reconoci$\mathrm{do}^{31}$. Lo característico de la ley 903/1977 es que, salvo excepciones muy concretas $^{32}$, configura la igualdad entre hombres y mujeres como un concepto

30. BALlestrero, Maria Vittoria: «La Ley italiana sobre acciones positivas. Una primera lectura". Relaciones Laborales, vol. 1993-I, p. 209. "La eficacia vinculante del principio de paridad de trato y de la correlativa prohibición de discriminación a cargo de la autonomía privada puede servir para proteger a la mujer contra tales comportamientos injustificados o penalizadores de las empresas, pero no es ciertamente suficiente para promover las oportunidades ocupacionales y para mejorar la calidad, sobre todo profesional, del trabajo de las mujeres" (GHERA, Edoardo: "Azioni positive e pari opportunità". Giornale di diritto del lavoro e di relazioni industriali, núm. 65, 1995 , p. 7 -la traducción del italiano es mía-). Desde 1978 se han puesto en marcha en Italia diversas medidas específicamente orientadas a promover el empleo femenino, entre las que se pueden destacar el haber elevado en 1978 a veintinueve años el límite de edad para que las mujeres puedan acceder a los contratos de formación-empleo (contratti di formazione-lavoro, regulados en la ley italiana 285/1977, de 1 de junio); un incremento en la duración de las ventajas fiscales para los empresarios que contraten a trabajadoras jóvenes; un mayor apoyo fiscal a los empresarios que contraten a tiempo indeterminado a mujeres; o los convenios entre empresas y Comisiones para el empleo orientadas a promover el empleo femenino (para otras medidas, también orientadas a acabar con la segregación profesional, vid. BALLESTRERo, Maria Vittoria: "Le azioni positive fra eguaglianza e diritto diseguale: una politica e i suoi strumenti. Eguaglianza sostanziale, pari opportunità, azioni positive". En BALLESTRERO, Maria Vittoria y TREU, Tiziano (a cura di): Commentario sistematico alla legge 10 aprile 1991, n. 125. Azioni positive per la realizzazione della parità uomo-donna nel lavoro. En Le Nuove Leggi Civili Commentate, vol. 17-I, enero-febrero 1994, en especial pp. 17-19). La ley 125/1991 supone un paso adelante en este camino.

31. Ballestrero, M. V., "Le azioni positive fra eguaglianza..., cit.", p. 11.

32. El artículo 1.2 califica de discriminaciones directas las referidas al estado civil o al embarazo de la trabajadora: El artículo 1.5 prevé taxativamente en qué sectores de actividad se acepta que se tome en cuenta de forma decisiva en el acceso a un determinado puesto de trabajo el sexo de los candidatos (espectáculos, moda...). Se admite asimismo la pervivencia de regímenes diferenciados por sexo en materia de edad de jubilación (cincuenta y cinco años para las mujeres, sesenta en el caso de los hombres, en el sector privado). 
estrictamente formal y simétrico, a cuyos ojos trabajadores y trabajadoras han de ser tratados exactamente de igual manera, sin que el género adquiera ninguna relevancia en el ámbito de la relación laboral. Las insuficiencias de este modelo de igualdad, que obliga a las mujeres a adaptarse a la forma de trabajar de los varones si quieren tener acceso al ámbito laboral, sin tomar en consideración las diferencias femeninas, y que no incrementa las oportunidades de las mujeres de alcanzar un puesto de trabajo remunerado (oportunidades notablemente limitadas respecto a las de los varones en general, sobre todo por el peso de las obligaciones familiares, que hoy por hoy siguen recayendo predominantemente sobre los hombros de las mujeres) hicieron que, impulsado por la Recomendación del Consejo 84/635/CEE, se pusiese en marcha en 1986 el procedimiento legislativo que llevaría a la aprobación, el 20 de marzo de 1991, de la ley núm. 125 de ese año ${ }^{33}$.

La ley 903/1977, salvo excepciones puntuales, toma como referencia, igual que hace el Derecho del Trabajo tradicional, a un sujeto neutro, que encaja en el modelo asumido en general por los ordenamientos jurídicos desde la Revolución Francesa: varón, blanco, adulto, sano y propietario ${ }^{34}$, y pretende aproximar a ese modelo a las mujeres trabajadoras, mediante normas simétricas, ignorando sus diferencias. El planteamiento de base de la ley del año 1991 es completamente diverso ${ }^{35}$ : se valora jurídicamente "lo específicamente femenino", y a partir de esa valoración de las diferencias que caracterizan a las mujeres, se avanza hacia la consecución de la igualdad de oportunidades en el trabajo en el respeto a esas diferencias, a tales especificidades.

El fin inmediato de la ley (favorecer la ocupación femenina) se reconduce al principio de igualdad material formulado en el artículo $3.2 \mathrm{CI}$ : se trata de

33. Sobre el largo iter parlamentario de esta ley, puede verse BallESTRERO, M.V., "La Ley italiana..., cit.., pp. 208-209. La ley núm. 125 de 1991, de 10 de abril, de acciones positivas en favor de las mujeres trabajadoras fue publicada en la Gazzetta Ufficiale núm. 88, de 15 de abril de 1991.

34. Incluso las normas protectoras del trabajo femenino de tintes paternalistas que se han puesto en práctica desde el nacimiento del Derecho del Trabajo no han hecho sino reflejar tales valores tipicamente masculinos, en lugar de valorar las demandas de las mujeres y su forma de trabajar (Guaglianone, Luciana: "Le azioni positive. Modelli e tipologie", en M. V. Ballestrero y T. Treu (a cura di), op. cit., pp. 28-29).

35. La relación entre ambas leyes no está exenta de polémica doctrinal, una polémica que en última instancia se reconduce a la que existe respecto a la relación entre el primer apartado del artículo 3 CI (principio de igualdad formal) y el segundo apartado de ese mismo artículo (principio de igualdad material), que es donde se halla el fundamento constitucional de la presente ley, en conexión también con los artículos 4 (exigencia de asegurar el goce efectivo del derecho al trabajo) y $37 \mathrm{CI}$ (derecho a un tratamiento igual en el marco de la relación laboral). Mientras algunos autores defienden que ambas leyes están unidas por una línea de continuidad, para otros entre una y otra se produce una ruptura total (AINIs, Michele: "Azioni positive e principio di eguaglianza". Giurisprudenza Costituzionale, vol. 37-I, 1992, p. 591, autor que defiende también la idea de que la relación entre igualdad formal e igualdad material es de conflicto radical, y no de complementariedad), que entre otros factores se reflejaría (o más bien sería consecuencia de ello) en un cambio de visión de la igualdad, que pasaría de ser valorada desde una perspectiva eminentemente individual a una colectiva, en la que la pertenencia a un grupo adquiere un peso decisivo. 
dotar de relevancia a las diferencias que, derivadas de sus características esenciales o de su pertenencia a colectivos diversos, existen entre las personas, permitiendo a dichas personas, mediante la eliminación de las consecuencias desfavorables que se ligan a la posesión por su parte de tales características, gozar de iguales oportunidades en el acceso y disfrute de bienes escasos. En ocasiones la eliminación de tales consecuencias desfavorables y la garantía de iguales oportunidades requerirá la adopción de medidas desiguales para unos sujetos y para otros, tratando de reequilibrar la posición de los tradicionalmente más desfavorecidos. Algunas de tales medidas desiguales podrán incluso incidir de forma decisiva y contundente en el resultado al que se tiende. Estas medidas más incisivas (reservas de plazas, objetivos numéricos, programas de contratación y promoción preferente) entrarían también dentro del ámbito de la ley comentada, aunque la ley no las impone en ningún caso y, naturalmente, no son imprescindibles en todos los supuestos para lograr la igualdad de oportunidades que la ley pretende ${ }^{36}$.

Los sujetos legitimados para promover la puesta en marcha de acciones positivas en el marco de la ley italiana son las instituciones, los empleadores públicos y privados, que pueden promover iniciativas incluso unilateralmente, y las organizaciones sindicales nacionales y/o territoriales. El papel promocional de las instituciones será particularmente interesante, por ser prácticamente los únicos sujetos con capacidad de iniciativa en el ámbito del sector de trabajo autónomo, para el cual también está prevista en esta ley la adopción de medidas de acción positiva (art. 1.2 b)).

La adopción de las acciones positivas previstas en la ley italiana tiene en la mayor parte de los casos carácter voluntario, primándose la implantación vía negociación colectiva de tales acciones en la empresa privada. En el ámbito, sin embargo, de las Administraciones públicas la puesta en marcha de planes de acción positiva en favor de las mujeres que trabajan en ellas tiene carácter obligatorio a todos los niveles ${ }^{37}$ (art. 2.6), si bien el plazo de un año

36. El Ministerio italiano de Finanzas promovió en 1992, «en el ámbito de los fines a los que se refiere el artículo 1 de la ley 125/1991, de 10 de abriln, un concurso a funcionario de finanzas de octava categoría en el que se reservaron el veinte por ciento de las plazas a las mujeres, un ejemplo de cuota amparada por la ley que comentamos. La ley italiana 223/1991 ha previsto la obligación para las empresas de más de diez trabajadores de reservar una cuota de entre el doce y el veinte por ciento de los puestos a los trabajadores de ciertos colectivos indicados en el artículo 25 de la ley, entre los que figuran "las categorias determinadas, incluso para áreas territoriales concretas, por deliberación de la Comisión regional para el empleo, aprobadas por el Ministro de Trabajo y de Seguridad Social. ¿Podrían figurar entre estas categorías, elegidas por su condición de "fasce debolin, las mujeres? La respuesta que dan Santucci y Zoppoli, a los cuales me remito para el estudio de su razonamiento, es negativa (vid. SANTUCCI, Rosario y Zoppoli, Lorenzo: "Finalità della legge e questioni di costituzionalità". En GAETA, Lorenzo y Zoppoli, Lorenzo (a cura di): Il diritto diseguale. La legge sulle azioni positive. Turín: G. Giappichelli Editore, 1992, en especial pp. 21 y ss). Estos autores consideran que los sistemas de cuotas no están en sintonía con el espíritu de la ley 125/1991.

37. La adopción de los mismos ha de hacerse habiendo escuchado previamente a los representantes del personal o a los sindicatos, así como a las instituciones públicas de paridad, pero 
que se da a las Administraciones para la adopción de estos planes, al hallarse carente de sanción, no resulta operativo en la práctica.

Este elemento de obligatoriedad puede llamar la atención si lo comparamos con lo que ocurre en el marco de la misma ley respecto al sector privado, pero no resulta extraño si lo comparamos con los modelos adoptados en otros países comunitarios, donde ocurre lo mismo. En la esfera de la Administración Pública alemana existía desde 1994 una Ley Federal para la Promoción de las Mujeres (Frauenförderungsgesetz), ahora sustituida por la llamada Gleichstellungsdurchsetzungsgesetz, que entró en vigor el 5 de diciembre de 2001. Esta ley incorpora en su $₫ 8$ la obligación para todos los sectores, organismos e instituciones de la Administración Federal (incluidos los Tribunales) de formar, contratar y promover con carácter preferente a mujeres, a igualdad de méritos (respetando así los principios de mérito y capacidad que han de determinar, según el artículo 33.2 GG, el acceso a la función pública), en aquellos sectores en que estén infrarrepresentadas (esto es, donde su presencia sea inferior al cincuenta por ciento), siempre que las circunstancias presentes en la persona de otros aspirantes no inclinen la balanza a favor de éstos. Asimismo se obliga a invitar a las entrevistas y procesos de selección a tantos hombres como mujeres que reúnan la cualificación exigida para el puesto, si hay un número suficiente de mujeres que han solicitado el puesto en cuestión ( $(7)$. Los comités de selección han de estar compuestos, por un número igual de hombres que de mujeres. El $₫ 9$ de la Ley determina qué criterios y cuáles no pueden ser tenidos en cuenta a la hora de valorar la cualificación de los aspirantes, prohibiendo expresamente la consideración de aquéllos que normalmente juegan en perjuicio de las mujeres (interrupción de la actividad profesional o reducción de la jornada de trabajo en el pasado debido a la asunción de obligaciones familiares, número de años trabajados, ingresos de la pareja, etc.). La Ley contempla también en su $₫ 11$ el diseño periódico con carácter obligatorio de planes orientados a elevar los niveles de igualdad entre hombres y mujeres dentro de cada sector, organismo o institución de la Administración Federal, planes que, a partir de una descripción de la situación de las mujeres en comparación con la de los varones en el organismo concreto de que se trate, han de prever medidas concretas para eliminar la infrarrepresentación de las mujeres, cuyo cumplimiento se revisa periódicamente. El Gobierno Federal, por su parte, queda obligado a presentar

sin que haya en realidad una genuina negociación, como sí que ocurre en el ámbito privado. Las razones que pueden justificar esta opción legislativa pasan por la constatación de que en el sector público, pese a una mayor presencia de mujeres que de varones (en el caso de Italia la presencia femenina alcanza el sesenta por ciento), las mujeres no están homogéneamente repartidas entre todos los ámbitos de actividad ni, sobre todo, entre todos los niveles organizativos, dándose de forma especialmente clara fenómenos de segregación, tanto en el plano horizontal como, particularmente, en el vertical. La paridad formal que caracteriza el acceso a la función pública no se corresponde posteriormente con una genuina igualdad de oportunidades para las mujeres en el seno de la Administración. 
cada cuatro años un informe ante el Bundestag en el que se analice la situación de las mujeres en relación a la de los varones dentro del ámbito de la Administración Federal $(\$ 25)^{38}$.

También en Austria existen normas, tanto a nivel federal (Ley Federal de Igualdad de Trato, de 1993 ${ }^{39}$ ) como en algunas Provincias, que obligan a las Administraciones públicas a contratar o promover a mujeres preferentemente en todos los niveles, hasta que éstas estén representadas en un porcentaje no inferior al cuarenta por ciento, y además se prevén sanciones disciplinarias para las autoridades administrativas que vulneren estas normas, unidas a indemnizaciones económicas para la persona a la que indebidamente hayan dejado de aplicarse (aunque no se exige su incorporación al puesto del que indebidamente se le ha privado).

Igualmente en Bélgica cada organismo del sector público está obligado a establecer un plan de igualdad de oportunidades, que puede incluir la adopción de medidas de acción positiva ${ }^{40}$. Algo similar se prevé en Finlandia tanto

38. Otras medidas de acción positiva en favor de las mujeres tanto en el sector público como privado en el caso de Alemania pueden verse en el Programm "Frau und Beruf "..., cit.

39. Art. 40 de la Ley Federal Austriaca de Igual Trato, de 1993: "1. Los representantes del empleador están obligados a adoptar medidas apropiadas conforme a las exigencias establecidas en el plan de promoción de las mujeres [que se elabora periódicamente en el ámbito de cada Ministerio], de cara a abolir (i) una infrarrepresentación real de las mujeres con referencia al número total de personal permanente y de cargos individuales, asi como (ii) desventajas reales padecidas por las mujeres en el empleo. 2. Las mujeres están infrarrepresentadas si su proporción en el número total ( $i$ ) de las empleadas fijas en el respectivo nivel de servicio para empleados civiles o (ii) de los cargos desempeñados por las empleadas fijas en el respectivo nivel de servicio, es inferior al cuarenta por ciento en la respectiva esfera de actividad de la administración (...). Art. 42: "Las candidatas femeninas que demuestren poseer al menos la misma cualificación que el candidato masculino más idóneo para un puesto fijo babrán de ser preferidas en el proceso de contratación, de acuerdo con las exigencias establecidas en el plan de promoción de las mujeres, basta que la proporción de mujeres dentro de la esfera de actividad de la respectiva Administración sea al menos del cuarenta por ciento del número total de empleados fijos (...). . El artículo 43 establece una regla similar en el caso de ascensos. El artículo 44, por último, establece que "las mujeres tendrán acceso preferente a los cursos de formación básica y superior que las cualifique para cargos y empleos superiores de acuerdo con las exigencias establecidas en el plan de promoción de las mujeres.. En el año 2001 estos preceptos (arts. 42-44) fueron objeto de reforma para introducir en ellos sendas cláusulas de apertura, que garantizan esa contratación, ascenso o acceso a la formación de las mujeres con carácter preferente en situaciones de infrarrepresentación femenina siempre que en la persona del candidato masculino no concurran otras razones de peso que hagan que sea su candidatura la preferida.

40. La ley belga que regula actualmente la igualdad de trato entre hombres y mujeres es de 7 de mayo de 1999 (Loi sur l'égalité de traitement entre bommes et femmes en ce qui concerne les conditions de travail, l'accès à l'emploi et aux possibilités de promotion, l'accés á une profession indépendante et les régimes complémentaires de sécurité sociale). Su artículo 6 autoriza genéricamente la adopción de medidas que se orienten a promover la igualdad de oportunidades entre hombres y mujeres. Hay diversas Reales órdenes que regulan aspectos precisos de la materia, como una de 27 de febrero de 1990, modificada por otra de 24 de agosto de 1994, por la que se establecen medidas para el fomento de la igualdad de oportunidades entre los hombres y las mujeres en los servicios públicos, entre las que se incluye la medida obligatoria citada. 
para el sector público como para el privado: desde $1995^{41}$ todos los empleadores, públicos y privados, están obligados a adoptar medidas activas de promoción de la igualdad y, si tienen más de treinta trabajadores, han de elaborar obligatoriamente planes para la igualdad de géneros, en el marco de los cuales se permite incluso el empleo de medidas moderadas de tratamiento preferente en favor de las mujeres.

El modelo sueco ${ }^{42}$ es parecido. La Ley Sueca de Igualdad de Oportunidades del año 1991, que desde el año 1994 ha sido objeto de diversas reformas, ordena al empleador que, en caso de infrarrepresentación de uno de los dos sexos en una determinada categoría o en un determinado nivel dentro de la empresa, intente contratar a solicitantes del sexo infrarrepresentado cuando se trate de cubrir nuevos puestos, con el objetivo de ir incrementando gradualmente la proporción de empleados de ese sexo en ese ámbito, salvo que exista alguna razón especial que justifique que no se actúe de esa manera, o que un comportamiento tal no se pueda exigir razonablemente del empleador, en vista de sus concretos recursos y circunstancias (sección 9). Según la sección 13 de esta Ley, es obligatorio (y se prevén diversas sanciones) para el empleador que tiene al menos diez trabajadores establecer anualmente un programa de igualdad (así como un plan de acción para garantizar la igualdad de pago), cuyos resultados se evalúan al año siguiente coincidiendo con la presentación del nuevo programa anual. En ese programa se ha de incluir una referencia a las medidas que sería necesario poner en marcha en el lugar de trabajo y a las medidas que el empresario está efectivamente dispuesto a implantar ese año, y habrá asimismo de referirse al desarrollo de las medidas propuestas el año anterior. La adopción de medidas de acción positiva (contratación o promoción preferente, básicamente ${ }^{43}$ ) no es obligatoria con carác-

41. La Ley finlandesa para la Igualdad entre Hombres y Mujeres, que entró en vigor el 1 de enero de 1987 y que ha sido objeto de varias reformas posteriores, estableció desde el primer momento que las medidas sistemáticas orientadas a lograr la igualdad entre géneros no suponen una vulneración de la prohibición de discriminación por razón de sexo.

42. Sigo en este punto en parte a MiGIROU, Kalliope: "Towards effective implementation of international women's human rights legislation", texto publicado en Internet (http://www.idea.int/women/parl/toc.htm), [pp. 8 y ss]; y BerGH, Lise: «Positive Maßnahmen zur Frauenförderung im öffentlichen Dienst Schwedens / Positive action for women in the Public Service of Sweden", en M. Knipp y A. Sporrer (eds.), op. cit., pp. 154 y ss. Vid. también SeVtlid MerrNO, Julia: "La mujer, sujeto constitucional de derechos: derecho al trabajo. IX Jornadas de Coordinación entre Defensores del Pueblo. Alicante: 5, 6 y 7 de octubre de 1994, pp. 247-248; y BORCHORST, Anette: "Gender equality law". En BERGQVIST, Christina y otras (eds.): Equal democracies? Gender and Politics in the Nordic countries. Oslo: Scandinavian University Press, 1999, pp. 190 y ss.

La Ley sueca insta asimismo al empresario a procurar que tanto hombres como mujeres presenten solicitudes para optar a puestos vacantes (sección 8).

43. Hay que tener en cuenta que en el acceso a la función pública, la Constitución sueca prevé, en el artículo 9 del capítulo 11, que sólo podrán ser tenidos en cuenta criterios objetivos como el mérito y la competencia, y la ley de 1994 sobre la Función Pública obliga a seleccionar a los candidatos en función de su competencia, pero autoriza expresamente a que, si hay "motivos particulares" que lo justifiquen, se pueda recurrir a otros criterios. 
ter general; a lo que sí está obligado el empresario es a garantizar sus esfuerzos para lograr que haya la misma proporción de hombres que mujeres en el seno de la empresa, algo que la Defensora para la Igualdad de Oportunidades se encarga de controlar, pudiendo incluso proponer ella misma a la Comisión de Igualdad de Oportunidades la imposición de sanciones a los empresarios incumplidores, $\mathrm{u}$ obligarles a adoptar medidas de «discriminación inversa". Por convenio colectivo se pueden mejorar o completar las medidas previstas por la ley ${ }^{44}$.

Hay otros países comunitarios donde la adopción de medidas de acción positiva está prevista también para las Administraciones Públicas, pero no reviste carácter obligatorio. En Irlanda ${ }^{45}$ se aprobó en 1974 una ley sobre no discriminación en materia de remuneración, tres años después otra sobre igualdad en el empleo, y a lo largo de los años ochenta se pusieron en marcha diversas medidas de acción positiva orientadas a fomentar la igualdad de oportunidades de hombres y mujeres dentro de la Administración irlandesa ${ }^{46}$, aunque no existe norma alguna que prevea explícitamente la obligatoriedad de establecer mecanismos de preferencia en la contratación o la promoción de mujeres en ámbitos en los que éstas estén infrarrepresentadas ${ }^{47}$. La Irish Employment Equality Act de 1977 sólo indicaba genéricamente que "no será ilegal organizar o proporcionar a personas de un sexo determinado, un tipo, una forma o una categoría de trabajo en el que estén infrarrepresentadas", y en esa línea van también la Employment Equality Act

44. No hay que olvidar tampoco la importancia de las medidas suecas en materia de conciliación de las responsabilidades profesionales y familiares, que están entre las más avanzadas dentro de los países comunitarios. Desde 1995 las excedencias subsidiadas vinculadas al nacimiento de un hijo alcanzan los cuatrocientos cincuenta días, de los cuales la mitad los disfruta la madre y la otra mitad el padre, si bien cualquiera de los progenitores puede ceder por escrito ese beneficio al otro miembro de la pareja, reservándose en cualquier caso treinta días ( $m e s$ del padre/mes de la madre") que no pueden ser cedidos (una previsión similar de cuatro semanas de permiso obligatorio mínimo para cada uno de los progenitores existe en Noruega). En Suecia asimismo el sesenta por ciento de los niños en edad previa a la escolarización obligatoria son atendidos en guarderías privadas o de titularidad municipal pero regidas por padres/madres trabajadores en régimen de cooperativa. Éste es un servicio básico que exigen los padres y las madres en un país en el que lo general es que ambos tengan un trabajo remunerado.

45. Fue la incorporación de Irlanda a las Comunidades Europeas en 1973 la que determinó notables transformaciones en ese país en la igualdad de trato jurídico entre hombres y mujeres, que hasta ese momento no existía plenamente. Hasta esa fecha, por ejemplo, las mujeres que trabajaban en la Administración tenían que dejar su empleo al contraer matrimonio, y estaban condenadas a ocupar los puestos más bajos de la Administración (algunos de los cuales estaban reservados en exclusiva para ellas).

46. Pueden verse más ampliamente en VOGEL-POLSKY, Eliane: “Los programas de acción positiva en provecho de las mujeres: 2. La práctica». Revista Internacional del Trabajo, vol. 104, núm. 3, julio-septiembre 1985, pp. 346-347.

47. Si la hay para corregir desequilibrios en la composición religiosa de la plantilla (BALLESTER PASTOR, María Amparo: Diferencia y discriminación normativa por razón de sexo en el orden laboral. Valencia: Tirant lo Blanch, 1994 (Colección Monografías, núm. 27), pp. 89-90, que envía a MACCRUDEN: "Affirmative action and fair participation: interpreting the Fair Employment Act 1989". Industrial Law Journal, vol. 21, núm. 3, 1992). 
de $1998^{48}$ y la Equal Status Act de 2000. Mucho menos incisivas son las normas francesas ${ }^{49}$, país en el que las acciones positivas en el sector público (a salvo de las recientes reformas constitucionales y legales en materia electoral, de las que no nos ocupamos en este trabajo) se han centrado fundamentalmente en la vertiente formativa, y a través de las cuales se aspira sobre todo a corregir la segregación vertical en la función pública, que hace que las mujeres se concentren fundamentalmente en los puestos más bajos de la escala jerárquica y que su presencia en los puestos de responsabilidad haya sido tradicionalmente muy escasa.

En el sector privado, por su parte, la tónica general en los países comunitarios estudiados suele ser, igual que en Italia, la de dejar a la voluntad del empleador o a lo que pueda decidirse en la negociación colectiva la adopción de planes de acción positiva, si bien en algunos casos su implantación se trata de estimular indirectamente a través de subvenciones. Es lo que ocurre en Italia, cuya ley 125/1991 sí incentiva económicamente la adopción voluntaria de acciones positivas por parte de los empleadores privados, teniendo en cuenta que las medidas acordadas bilateralmente entre el empleador y los sindicatos gozarán de preferencia a la hora de acceder a la financiación pública prevista en la ley (art. 2.4) $)^{50}$. También en Alemania, donde no existe ninguna ley de promoción de las acciones positivas en el sector privado (la reciente Gesetz zur Durchsetzung der Gleichstellung von Frauen und Männern, de 2001, se

48. Su artículo 24,1 establece expresamente que "las disposiciones de esta ley no excluyen las medidas para promover oportunidades iguales para bombres y mujeres, en especial mediante la remoción de las desigualdades existentes que afectan a las oportunidades de las mujeres en las áreas de acceso al empleo, formación vocacional, y condiciones de trabajo y de promoción.

49. Puede verse con más detalle VOGEL-POLSKY, E., op. cit., pp. 347-348.

50. Se pregunta Guaglianone si las organizaciones sindicales están en condiciones de representar a los trabajadores tradicionalmente discriminados (a las trabajadoras) integrados en ellas, o si es un tanto utópico suponer que los sindicatos vayan a poner en peligro el apoyo de los sectores más fuertes dentro de los mismos por ayudar a los sectores más débiles cuando los intereses respectivos entren en conflicto, como suele ocurrir en el caso de las políticas de igualdad de oportunidades, y, en definitiva, hasta qué punto son los interlocutores más válidos en esta materia (Guaglianone, L., op. cit., pp. 44-45). También se refiere a esto Barbera, Marzia: “La nozione di discriminazione", en M. V. Ballestero y T. Treu (a cura di), op. cit., p. 53. En cuanto a las acciones positivas efectivamente puestas en marcha y financiadas con fondos públicos al amparo de esta ley, parece que responden más hasta el momento a concretas necesidades aisladas de la empresa que a proyectos globales de mejora en el aprovechamiento de los recursos humanos y en particular en la valoración del trabajo femenino. Los sectores que más se han interesado por este tipo de medidas han sido, por este orden, el sector servicios, el de la formación, y la industria, y en atención al territorio, han sido sobre todo empresas del norte del país, el área más industrializada, las que más han solicitado las ayudas financieras que acompañan a la puesta en marcha de las medidas previstas en esta ley. Dado lo limitado de los recursos económicos de que dispone el Comité Nacional de Paridad para cubrir estos proyectos, ha debido afinar en la selección de los que iban a resultar efectivamente financiados, habiéndose dado especial relevancia en los primeros años, no tanto al hecho de que los proyectos fuesen fruto de la negociación colectiva, sino a la importancia de la empresa (en el sentido de que, por ser empresas conocidas, pudiesen motivar a otras empresas a adoptar políticas similares) y a su presencia en sectores en los que las dificultades para el empleo femenino se hubiesen revelado como especialmente graves (todos estos datos los extraigo de Guaglianone, L., op. cit., p. 36, nota 50). 
aplica sólo en el ámbito de la Administración Federal y de la organización de los Tribunales), el Gobierno federal trata de fomentar a través del diálogo con los actores sociales la igualdad de oportunidades para las mujeres, apoyando a las empresas que ya la promueven activamente, y no se descarta la elaboración futura de normas en esta materia que se dirijan a elevar los niveles de igualdad real entre hombres y mujeres en esos sectores.

Particularmente avanzados aparecen en el sector privado, en todo caso, los sistemas neerlandés y noruego. En los Países Bajos ${ }^{51}$ el texto de la Constitución no hace referencia a las medidas de acción positiva. La Ley de Igualdad de Trato para Hombres y Mujeres de 1980 (elaborada para implementar la Directiva comunitaria 76/207) permitía el tratamiento preferente en favor del sexo infrarrepresentado. $\mathrm{Al}$ aplicarse fundamentalmente en los niveles profesionales más bajos llego a ser frecuente que fuesen los varones quienes se beneficiasen de tales medidas. Ello llevó a sustituir en 1989 esa referencia legal al "Sexo infrarrepresentado" por una referencia expresa a las "mujeres", en la línea además de lo establecido en el antiguo artículo 2.4 de la Directiva comunitaria 76/207. El artículo 5 de la Ley dice ahora que "se permitirá un trato distinto entre bombres y mujeres cuando el objetivo sea colocar a las mujeres en una posición preferente de modo que se eliminen o se reduzcan las desigualdades de hecho y en la medida en que la distinción que se bace esté razonablemente relacionada con el fin perseguido por la medida. El artículo 3, por su parte, relativo al proceso de contratación, dice que se prohíben toda clase de discriminaciones, a menos que sea aplicable una excepción legal a esta regla de igualdad. Una de estas excepciones legales sería la aplicación de una medida de tratamiento preferente en favor de las mujeres, pero en tal caso es necesario que el empleador advierta esta circunstancia en la oferta de empleo. La posibilidad de las medidas de tratamiento preferente en los Países Bajos aparece en todo caso como una excepción lícita a la regla general, que es el principio de igualdad de trato. La Comisión para la Igualdad de Trato ha elaborado desde 1994 una doctrina que aplica en los casos en que se hace uso de medidas de tratamiento preferente en el proceso de contratación: en primer lugar, el empleador que desee aplicar una de estas medidas ha de cuantificar el número de hombres y de mujeres que trabajan en los distintos niveles de la empresa; a continuación ha de fijar, mediante estadísticas, el número de hombres y mujeres que reúnen la cualificación necesaria para desempeñar tales empleos en un ámbito territorial determinado en el que se ubica la empresa. Ello le permitirá saber si las mujeres están infrarrepresentadas y establecer objetivos numéricos que habrán de satisfacerse mediante diversas medidas de tratamiento preferente en favor de las mujeres. Estas medidas tendrán que estar limitadas temporalmente (hasta el momento en que se satisfagan los

51. Incorporo en este punto los datos aportados por SJERPS, Ina: "Positive Maßnahmen zur Frauenförderung im öffentlichen Dienst der Niedelande / Positive action for women in the public service in The Netherlands", en M. Knipp y A. Sporrer (eds.), op. cit., pp. 86 y ss. 
objetivos) y habrán de ser proporcionadas, en función del grado de infrarrepresentación que padezcan las mujeres. Normalmente no se emplean medidas que supongan dar preferencia a la contratación de una mujer que, pese a reunir una cualificación mínima suficiente para desempeñar el empleo de que se trate, esté menos cualificada que otros candidatos varones. La Comisión se ha pronunciado también a favor de la legalidad de las medidas del empleador que suponen conceder un plus retributivo o plazas de guardería a las trabajadoras con hijos pequeños, siempre que las mujeres estén infrarrepresentadas en la empresa y que se incluyan cláusulas de apertura que permitan excepciones a la regla general en supuestos específicos de varones que en principio estarían excluidos de su aplicación ${ }^{52}$.

La ley noruega en materia de igualdad, pese a que este país no forma parte de la Unión Europea, ha de respetar las exigencias de la normativa comunitaria, dada la pertenencia de Noruega al Espacio Económico Europeo. Esa ley es la Ley para la Igualdad de Géneros, de 1978, que se aplica en todos los ámbitos y sectores de la sociedad y que parte de la idea de que se requieren esfuerzos activos para promover la igualdad real de las mujeres ${ }^{53}$. Por ello se acepta la legitimidad de las medidas de acción positiva en favor de las mujeres, que normalmente se concretan a través de los convenios colectivos, siempre en el marco de la ley, aunque ésta no regula directamente el empleo de reservas de plazas en el ámbito laboral (que sí que están permitidas, si bien no son apenas utilizadas). Se ha introducido expresamente en la ley, y esto puede resultar curioso, la posibilidad de hacer uso de medidas de acción positiva en favor de los varones en ámbitos muy concretos, relacionados con el cuidado de niños pequeños, donde los varones están notablemente infrarrepresentados ${ }^{54}$. Tales medidas en favor de los varones serían promovidas directamente por la Defensora para la Igualdad de Oportunidades, no por convenio colectivo.

En Dinamarca hay desde el 30 de mayo de 2000 una nueva Ley sobre Igualdad de Género (Act on Gender Equality) que autoriza expresamente la puesta en marcha de medidas encaminadas a promover la igualdad de género ${ }^{55}$. Los distintas instituciones públicas danesas quedán obligadas a integrar la

52. Vid. al respecto la reciente sentencia del TJCE «H. Lommers v. Minister van Landbouw, Natuurbeheer en Viseerij, (Lommers), de 19 de marzo de 2002 (asunto C-476/99).

53. Igual que ocurre en todos los países nórdicos, salvo Dinamarca, e igual que ocurrió en los Países Bajos, según hemos visto, la ley fue inicialmente formulada de una manera totalmente neutra respecto al género, pero fue modificada posteriormente para incluir una referencia expresa a la idea de que lo que se desea mejorar en particular es la posición de las mujeres (BORCHORST, A., op. cit., pp. 191-192).

54. Algo similar ocurre también en Dinamarca (ibidem, p. 197).

55. Tales medidas siguen apareciendo como un instrumento necesario toda vez que las mujeres danesas cobran en torno a un ochenta por ciento de lo que cobran los varones, y están notablemente infrarrepresentadas tanto en el Gobierno como en los puestos directivos de las grandes empresas (en 1998 sólo ocupaban el once por ciento de los puestos directivos de las cincuenta mayores empresas del país nórdico). 
igualdad de género en todas sus políticas (mainstreaming) y, si tienen más de cincuenta empleados, a presentar informes cada dos años en los que aportarán información sobre las políticas de igualdad de género que están desarrollando y estadísticas acerca del reparto de puestos entre sexos dentro de su plantilla. En el sector privado se ha intentado poner en marcha en Dinamarca ciertas estrategias que hagan posible un cambio de actitud susceptible de corregir la infrarrepresentación femenina, sobre todo en determinados sectores y en determinados niveles, fundamentalmente estimulando a los empresarios para que tomen conciencia del potencial humano infrautilizado que representan los miembros de los colectivos tradicionalmente discriminados.

En esta línea se orienta también la política luxemburguesa en esta materia. Hasta ahora ${ }^{56}$ se han puesto en marcha en Luxemburgo diversas medidas de acción positiva, algunas de las cuales han recibido subvenciones oficiales ${ }^{57}$, dirigidas fundamentalmente a elevar el nivel formativo de las trabajadoras y a proporcionarles una formación específica en materia de gestión y dirección de empresas, pero el Gobierno luxemburgués está desarrollando además una labor dirigida a los empresarios de cara a persuadirles de que las acciones positivas contribuyen a un mejor aprovechamiento de los recursos humanos y del potencial de sus empleados, sean hombres o mujeres.

En Francia el artículo L. 123-3 del Code du Travail (ley núm. 83-635, de 13 de julio de 1983) dispone en cualquier caso que el principio de igualdad no supone un obstáculo para la puesta en marcha de medidas temporales en beneficio exclusivo de las mujeres con vistas a establecer la igualdad de oportunidades entre hombres y mujeres, en concreto remediando las desigualdades de hecho que limitan sus oportunidades. El Parlamento francés aprobó el 9 de mayo de 2001 la Ley núm. 2001-397 relativa a la igualdad profesional entre hombres y mujeres, tanto en el ámbito de la empresa privada (donde se prevé la obligación de incluir la igualdad entre hombres y mujeres en todas las materias objeto de negociación; es asimismo obligatorio poner en marcha planes de igualdad profesional, negociados entre el empresario y los representantes de la plantilla) como en el de la función pública (donde se prevé una representación equilibrada de hombres y mujeres en todos los comités de selección). Esta ley ha tratado también de reforzar la representación igualitaria de hombres y mujeres en el contexto de las elecciones profesionales. Por último, trata de mejorar las condiciones de tra-

56. Sejún las informaciones aportadas por el Tercer Informe periódico presentado en Nueva York el 19 de enero de 2000 por la Ministra de Promoción Femenina del Gran Ducado de Luxemburgo ante el Comité para la Eliminación de la Discriminación contra las Mujeres de la ONU respecto al cumplimiento del Convenio CEDAW. Vid. también los interesantes datos aportados por el Informe de la Comisión luxemburguesa para la Igualdad de Oportunidades entre Mujeres y Hombres y para la Promoción Femenina, presentado el 25 de febrero de 1999 (documento parlamentario núm. 4498, Débat d'orientation sur la participation des femmes dans la prise de décision).

57. Véase el artículo XXVII de la Ley luxemburguesa de 12 de febrero de 1999, Loi portant sur la mise en ceuve du Plan d'Action National pour l'Emploi, aplicable sólo al sector privado. 
bajo tanto de hombres como de mujeres en lo que se refiere a duración de la jornada laboral y al trabajo nocturno.

En el Reino Unido, por último, entró en vigor en 1975 la Sex Discrimination Act, modificada en $1986^{58}$. Han sido las autoridades locales las que han dado los pasos más decididos en el Reino Unido en la lucha contra la discriminación por razón de sexo y en pro de la igualdad de oportunidades, haciendo que los empresarios tomen conciencia de que discriminar a las mujeres por su condición de tales (o a los miembros de minorías étnicas, o a los discapacitados) supone, entre otras cosas, desaprovechar e infrautilizar mano de obra cualificada y preparada para el ejercicio de las funciones que se le encomienden. La reserva de plazas y las restricciones en favor de las mujeres o de los miembros de minorías étnicas en los procesos de contratación están prohibidas en el ámbito de aplicación de la Sex Discrimination Act y de la Race Relations Act, pero sí autorizan estas leyes las medidas educativas y formativas destinadas en exclusiva a los miembros de estos colectivos, e incluso el establecimiento de objetivos numéricos, cuya no satisfacción en un período determinado puede indicar la existencia de fenómenos encubiertos (a veces incluso inconscientes) de discriminación contra esos colectivos. Las principales medidas de acción positiva efectivamente adoptadas se han centrado principalmente en el campo de la formación, pero se han adoptado además medidas diversas para asegurar en lo posible que el proceso de selección de nuevos empleados sea lo más neutral posible respecto a los criterios tradicionalmente utilizados para discriminar a unos candidatos frente a otros; para garantizar la igualdad de oportunidades en cuanto a los ascensos incluso a quienes trabajan a tiempo parcial (mujeres, fundamentalmente); para facilitar que se puedan compatibilizar obligaciones profesionales y obligaciones familiares; y para mejorar la formación de las empleadas. La adopción de programas voluntarios de acción positiva por parte de los empleadores públicos y privados $^{59}$ no está estimulada económicamente de ninguna manera.

58. La relevancia del fenómeno de la discriminación racial en el Reino Unido ha motivado que exista también en este país una importante normativa referida a la discriminación por motivos de raza, en concreto la Race Relations Act de 1976. Sobre la discriminación racial en Gran Bretaña, vid. AARON, Benjamin: "Discrimination based on race, color, ethnicity and national origin". En SCHMIDT, Folke (ed.): Discrimination in employment. A study of six countries by the Comparative Labour Law Group. Estocolmo: Almqvist \& Wiksell International, 1978, en especial pp. 57-58, y 67 y ss. Sobre la Race Relations Act de 1976, ibidem, pp. 89 y ss.

59. Uno de esos programas es el llamado Opportunity 2000, en el marco del cual numerosas empresas británicas (algunas tan conocidas como la BBC o British Airways) se han comprometido voluntariamente a incrementar los niveles de igualdad de oportunidades para las mujeres dentro de ellas. El programa de estrategias elaborado por cada una de las empresas para lograr ese objetivo ha dependido de las circunstancias específicas concurrentes en cada una de ellas: mientras que algunas han centrado su acción en medidas orientadas al cuidado de los hijos pequeños de las trabajadoras (para facilitar la compatibilidad entre obligaciones familiares y obligaciones profesionales), otras han establecido objetivos numéricos indicativos del número de mujeres que la empresa se compromete a incorporar a su plantilla o a ascender a puestos de responsabilidad en un determinado plazo de tiempo, para corregir situaciones de infrarrepresenta- 
Por otra parte, la ley italiana 125/1991 obliga a las empresas con más de cien trabajadores a informar cada dos años, como norma general, sobre la situación de los trabajadores y trabajadoras integrados en su plantilla y sobre sus condiciones de trabajo. En Francia ${ }^{60}$ se impone también a las empresas la obligación de presentar anualmente un informe escrito sobre las condiciones de empleo y de formación de trabajadores y trabajadoras en los distintos niveles. Sobre todo en el caso de la discriminación indirecta, se hace imprescindible para la parte actora contar con datos estadísticos fiables como éstos, porque particularmente en esos supuestos la prueba estadística adquiere una relevancia muy especial, y tal vez por ello los empresarios hasta ahora se han venido resistiendo con fuerza a proporcionarlos ${ }^{61}$. Según la ley italiana, lo que ha de probar el actor en caso de discriminación indirecta es que el impacto negativo desproporcionado sobre los miembros de un colectivo tradicionalmente marginado es el efecto de haber adoptado criterios de selección o de organización que perjudican en mayor medida al grupo al que pertenece el actor $^{62}$, aunque en ningún caso hay que probar ninguna intención discrimina-

ción femenina. Una detallada referencia a este programa puede verse en "Opportunity 2000". Equal Opportunities Review, núm. 41, enero-febrero 1992, pp. 20 y ss. La Sex Discrimination Act autoriza después de la reforma de 1986 a los sindicatos a reservar determinados puestos de sus órganos de dirección a mujeres, y permite a los empresarios ofrecer cursos de formación exclusivamente a mujeres para trabajos en los que están infrarrepresentadas.

60. Vid. más ampliamente MÉlin-Soucramanien, F., op. cit., en especial pp. 206 y ss.

61. La ley finlandesa sobre igualdad entre hombres y mujeres, de 1986, reconoce el derecho de los representantes de los trabajadores a acceder a toda la información de que disponga el empresario sobre salarios y relaciones de trabajo (siempre que el trabajador o los trabajadores a los que afecte dicha información den su consentimiento) si sospechan que existe una discriminación salarial por razón de sexo dentro de la empresa (art. 10). El mismo precepto de la ley obliga al empresario a proporcionar "sin demora" a una persona que se siente víctima de una discriminación por razón de sexo llevada a cabo por ese empresario, un informe escrito en el cual indique cuáles fueron los motivos de su actuación o aquellos elementos presentes en la persona favorecida que lo llevaron a tomar una decisión en perjuicio de esa otra que considera tal decisión discriminatoria, o las razones que justifican la percepción por su parte de un salario de una cuantía determinada a efectos de que pueda determinar si se está vulnerando la prohibición legal de discriminación salarial.

También regulan diversas obligaciones de información del empresario las secciones 21 y 33 de la Ley sueca de Igualdad de Oportunidades.

62. Ahora bien, incluso en los casos en que la parte actora haya proporcionado elementos que permitan al juez presumir la existencia de una discriminación, al empresario le cabe, según la ley italiana, la posibilidad de demostrar que una actuación de esta naturaleza (aparentemente discriminatoria) era esencial para el desarrollo de la actividad laboral, esto es, aportando razones objetiva y estrechamente job related, dependientes de sus facultades organizativas y necesarias (esenciales incluso, no simplemente oportunas o convenientes) para el funcionamiento de la empresa, que justifiquen tales tratos dispares por razón de sexo, en el caso de la discriminación indirecta; o la existencia de otras diferencias, al margen del sexo, que justifican el tratamiento diverso, en el caso de la discriminación directa. La de "requisitos esenciales para el desarrollo de la actividad empresarial" es una noción más estrecha que la de "motivos justificados aceptables por personas que piensen correctamente", utilizada por la jurisprudencia inglesa, o que las de "defensa del mercado" o la business necessity americana (véase al respecto TREU, Tiziano: "La legge sulle azioni positive: prime riflessioni”. Rivista Italiana di Diritto del Lavoro, vol. 10-I, 1991, p. 129). Si la duda persiste en la mente del juez, en vez de seguir la regla general marcada por el 
toria concreta por parte del empleador, porque no es necesario que la haya para que haya discriminación indirecta ${ }^{63}$.

La discriminación indirecta, en la que la pertenencia de los individuos discriminados a un grupo al que se perjudica como tal adquiere una relevancia de la que carecía en la discriminación directa (de perfiles más netamente individualistas), exige para ser remediada de acciones positivas, de comportamientos activos de promoción de igualdad de oportunidades que permitan la remoción de la situación discriminatoria en sí y de sus efectos perjudiciales, y la corrección de la misma de cara al futuro. Hay que desmontar la idea de normalidad organizativa de la estructura empresarial en la medida en que ésta acepte como "normal" la desigualdad de oportunidades de hombres y mujeres dentro de la misma ${ }^{64}$, introduciendo nuevas pautas organizativas y de gestión que valoren lo que de específico pueden aportar a la empresa las trabajadoras y que no las excluyan de determinados ámbitos (abiertamente o de forma encubierta, consciente o inconscientemente) por su condición de mujeres. De hecho, para las discriminaciones de carácter colectivo, aparte de los remedios que a título individual puedan promover los trabajadores, la ley italiana concede al Consejero regional de paridad una acción judicial que puede promover de oficio, "incluso aunque no sean individualizables de modo inmediato $y$ directo los trabajadores perjudicados por esta discriminación (art. 4.6). Pues bien, cuando triunfe una de estas acciones, el juez (art. 4.7) impondrá en la sentencia un plan obligatorio de remoción de las discriminaciones, definido por el propio empresario y que éste habrá de poner en marcha en el plazo

artículo 2697 del Código civil italiano en favor del mantenimiento del statu quo, se siguen las pautas que marca la Directiva comunitaria relativa a la carga de la prueba en esta materia, que favorecen la posición de la parte actora. Algo similar está expresamente previsto en las leyes británica (Sex Discrimination Act de 1975) y danesa (Ley danesa núm. 32, de 4 de febrero de 1976, modificada en 1986 y 1989, relativa a la igualdad de remuneración entre hombres y mujeres), que obligan al empresario a aportar razones que justifiquen su deçisión frente a una persona que alega haber sido discriminada por él.

63. Un ejemplo de una discriminación de este tipo que curiosamente todavía se mantiene es la exigencia por parte de los ferrocarriles estatales italianos de que quienés aspiran a ser contratados como ingenieros hayan de superar una cierta estatura, sin establecer diferencias entre la altura mínima que han de tener los hombres y la que han de tener las mujeres. En Alitalia, por su parte, la progresión salarial de los auxiliares de vuelo se conecta con los años de servicio efectivo y las horas de vuelo, lo que discrimina indirectamente a las mujeres que han disfrutado de permisos por maternidad.

64. BARBERA, M., op. cit., p. 54. Los fenómenos de discriminación indirecta suelen tener su origen en una sobrevaloración de los rasgos que acompañan al modelo de trabajador y de sujeto de Derecho asumido por la tradición liberal, o en una consiguiente infravaloración de los rasgos característicos de quienes no encajan en ese modelo. La aplicación de reglas uniformes de selección basadas en criterios de mérito que se han construido de acuerdo con aquellos modelos asumidos por la tradición liberal llevan a que los individuos pertenecientes, por su posesión de un cierto rasgo característico, a determinados colectivos queden de forma prácticamente inevitable (no necesariamente malintencionada por parte de quien lleva a cabo esa selección) fuera del reparto de bienes escasos (que puede ser el empleo en sí o los puestos que llevan aparejados un mayor prestigio o una mayor retribución económica o una mayor carga de responsabilidad). 
marcado por el juez ${ }^{65}$, plan que tiende no sólo a acabar con la situación discriminatoria detectada y con sus efectos, sino básicamente a corregir de cara al futuro situaciones discriminatorias que afectan a un número considerable de trabajadores de la plantilla de la empresa y a modificar las reglas organizativas y de gestión que las han generado. En Francia, igual que ocurre en Italia, también se autoriza al tribunal que juzgue la existencia de una discriminación laboral a imponer al empresario, si llega a la conclusión de que aquélla efectivamente existió, medidas orientadas a corregir esa situación de cara al futuro, y no sólo sus efectos sobre las personas concretamente afectadas.

En varios países europeos hay, por último, previsiones legales orientadas a garantizar la composición paritaria (o, al menos, un porcentaje mínimo de presencia de cada sexo) de órganos públicos o privados con funciones asesoras, consultivas o incluso decisorias en temas laborales. Es lo que ocurre en Bélgica, donde una ley federal de 20 de julio de 1990 , modificada en julio de 1997, dirigida a promover la presencia equilibrada de hombres y de mujeres en determinados órganos consultivos federales, obliga a las instancias encargadas de proponer a candidatos para los puestos vacantes en tales órganos a proponer a un hombre y a una mujer para cubrir esas vacantes. Igualmente obliga a que en el seno de cada uno de dichos órganos haya una presencia mínima de cada sexo de un tercio del total de los puestos. También en Dinamarca hay una previsión similar en la nueva Ley sobre Igualdad de Género de 2000: su artículo 8 obliga a que las comisiones y comités públicos y órganos similares estén compuestos en la misma medida por hombres y por mujeres. Se obliga asimismo a que para cualquier puesto en consejos, comisiones y comités públicos se proponga siempre a un hombre y a una mujer, con una misma cualificación, y que sea el Ministro correspondiente el que seleccione en cada caso a uno de los dos candidatos propuestos, siempre intentando conseguir un equilibrio global entre ambos géneros. A la Ministra de Igualdad de Género le corresponde vigilar el cumplimiento de estas previsiones. La presencia de mujeres en comisiones públicas se ha triplicado gracias a estas medidas, que ya se puso en marcha con una antigua Ley de 1985.

Igualmente efectiva se ha mostrado la previsión legal finlandesa, país en el que se ha pasado de un modelo flexible a un modelo que impone obligatoriamente una cuota de presencia de cada sexo en estos órganos. Una ley de 1985 estableció que tanto hombres como mujeres habrían de participar en los Consejos consultivos, en los comités y en los demás órganos de toma de decisiones de la manera más igualitaria posible. En 1995 esta ley fue modificada,

65. No se prevé la posibilidad, quizá más efectiva en la práctica, de obligar al empleador a negociar con los sindicatos el plan de acción positiva que se va a imponer a modo de sanción, aunque sí que tiene que consultar preventivamente a las organizaciones sindicales y al Consejero de paridad antes de definir el mismo. En los supuestos de existencia de una discriminación indirecta declarada será también posible sancionar al empresario culpable privándole de los beneficios económicos obtenidos hasta ese momento, y de la posibilidad de disfrutar en el futuro de concesiones de contratos públicos. 
obligando ahora a que la presencia de cualquiera de los dos sexos en todos los órganos de toma de decisiones suponga al menos el cuarenta por ciento ${ }^{66}$, lo que ha permitido casi duplicar el número de mujeres en tales órganos en apenas quince años. El modelo noruego es muy similar al modelo finlandés: la ley noruega prevé que en todos los comités, consejos y otros órganos similares de carácter oficial que tengan cuatro miembros o más, cada sexo ha de ocupar un cuarenta por ciento como mínimo de los puestos. Si tiene menos de cuatro miembros, la única previsión es que ambos sexos estén representados. Sólo en circunstancias excepcionales en las que se pruebe que es imposible encontrar un varón o una mujer suficientemente cualificados se podrá dejar de cumplir esta norma.

Habría que hacer una referencia, finalmente, a algunos de los organismos de promoción de la igualdad creados en algunos de los países europeos. En Noruega existe una Defensora para la Igualdad de Géneros, nombrada por el Gobierno y encargada de controlar el cumplimiento de las previsiones de la Ley para la Igualdad de Géneros, así como darle publicidad. Puede recibir quejas por violaciones de esta norma, e investigar otros casos de oficio. El incumplimiento de sus decisiones puede motivar un recurso ante el Comité de Apelación para la Igualdad de Géneros, un órgano no jurisdiccional que sí puede adoptar decisiones vinculantes en esta materia. También en Suecia existe la figura de la Defensora para la Igualdad de Oportunidades, que se creó en 1980 a través de la primera Ley para la Igualdad de Oportunidades. Esta Defensora, elegida por el Gobierno, aunque con un estatuto que garantiza su independencia, se encarga de asegurar el cumplimiento de las leyes en esta materia, y asume además funciones de promoción de la igualdad entre hombres y mujeres tanto en el ámbito profesional como educativo. Puede incluso presentar demandas en nombre y con el consentimiento de una trabajadora o solicitante de empleo por vulneración de la prohibición legal de discriminación, si considera que una sentencia sería útil para la aplicación del Derecho o hay otras razones que lo justifiquen. Una figura similar existe también en Finlandia: la Defensora finlandesa tiene derecho a recabar toda la información que necesite, tanto de las autoridades como de particulares, para controlar el correcto cumplimiento de las previsiones contenidas en la Ley sobre la Igualdad entre Hombres y Mujeres de 1987, e incluso puede imponer sanciones pecuniarias a quienes incumplan sus requerimientos; igualmente tiene facultades inspectoras y consultivas, y puede denunciar incumplimientos de la citada ley ante la Comisión finlandesa de Igualdad. En Dinamarca la Ley sobre Igualdad de Género de 2000 ha creado el Centro Nacional sobre Investigación e Información en materia de Igualdad de Género, y un Consejo sobre Igual-

66. Freixes SANJuÁn, Teresa: "El impacto diferencial de los sistemas electorales en la representación política de las mujeres. En VVAA: Hacia una democracia paritaria. Análisis y revisión de las leyes electorales vigentes (Actas del Seminario del mismo título celebrado en Toledo los días 8 y 9 de mayo de 1999), p. 90. 
dad de Género formado por especialistas en esta materia que tiene capacidad para resolver cuestiones de discriminación por razón de sexo que no estén sub iudice. Sus resoluciones son revisables en vía jurisdiccional, y también es posible acudir a los Tribunales para garantizar el cumplimiento de tales resoluciones por parte de los implicados.

La ley italiana regula ampliamente la composición y funciones de varios organismos de paridad creados en diferentes ámbitos territoriales. La figura principal es el Comité Nacional para la actuación de los principios de paridad de tratamiento y de igualdad de oportunidades entre trabajadores y trabajadoras, creado en el seno del Ministerio de Trabajo en 1983 por decreto ministerial. Entre sus funciones destacan las de carácter promocional y consultivo, pero no figuran entre ellas la tutela de las personas discriminadas ${ }^{67}$. En los Países Bajos funciona una institución similar, la Comisión para la Igualdad de Trato, un organismo cuya función principal es investigar los casos de presunta discriminación y emitir una opinión razonada sobre si esa presunta discriminación vulnera la legislación sobre igualdad de trato. Sus opiniones no son legalmente vinculantes, y aunque no es obligatorio acudir a la Comisión antes de ir a los Tribunales, lo normal es hacerlo; de hecho sólo unos pocos casos en materia de discriminación llegan al final a los Tribunales. También en los Países Bajos el Departamento Holandés para la Coordinación de las Políticas de Emancipación subvenciona una fundación (SLOV) que proporciona asistencia jurídica a las mujeres en estas circunstancias. Hay asimismo diversas organizaciones no gubernamentales en este país cuya misión es prestar asistencia legal a las mujeres en cuestiones relacionadas con la igualdad de trato, e incluso asumir su defenśa en juicio.

La figura que resulta potenciada en la ley italiana es la de los Consejeros de paridad (existentes en los niveles central, regional y de distrito), y ello por la mayor movilidad (y por tanto eficacia) que se presume de la actuación de un órgano unipersonal, aunque se les atribuye de forma excesivamente genérica la función de "desarrollar cualquier iniciativa útil para la realización de los fines previstos en la presente ley" (si bien ello también puede servir para conferirles mayor autonomía de acción). Son particularmente importantes sus poderes de iniciativa en los juicios de paridad, así como sus facultades investigadoras. En la ley no se menciona, sin embargo, cuáles son los instrumentos de que pueden valerse en el desarrollo de sus funciones ni los medios operativos con los que cuentan.

67. A este Comité Nacional se le critica, aparte de su composición excesivamente numerosa, el que algunas de sus funciones se solapan con las de otras instituciones, como la Oficina para la Condición Femenina (dentro del Departamento de la Función Pública) o la Comisión Nacional para la Realización de la Igualdad de Oportunidades entre Hombres y Mujeres creada en el seno de la Presidencia del Consejo de Ministros. Asimismo se critican, después de varios años de funcionamiento, sus constatadas carencias en el desarrollo de tareas inspectoras y de control, así como su incapacidad demostrada para haberse convertido en un auténtico punto de referencia en materia de paridad tanto para el Ministerio de Trabajo como para todas las instituciones que a distintos niveles desarrollan su labor en esa esfera. 
Similares tareas investigadoras en materia de discriminación encomendadas a determinados órganos públicos, que sirven para facilitar la labor del individuo que tiene que aportar evidencias de haber sido discriminado, están previstas en las irlandesas Anti-Discrimination Pay Act, de 1974, y Employment Equality Act, de 1977 (atribuidas a los llamados "oficiales de igualdad"), o en el Code du Travail francés (encomendadas a consejeros mandados por el Conseil de prud'bommes, o al Consejo mismo, bien de oficio, bien a instancia de parte. En Irlanda, la Irish Employment Equality Act (Ley irlandesa de igualdad en el empleo) atribuye a la Agencia para la Igualdad en el Empleo la función de prestar asistencia a los demandantes (varones y mujeres) en casos relativos a la igualdad de trato y la igualdad de retribución en el empleo. La Sex Discrimination Act británica de 1975 y la Sex Discrimination Order de Irlanda del Norte, de 1976, incluyen preceptos similares. 